\title{
REFLEXÕES INTRODUTÓRIAS AO MONOGRÁFICO «CIDADE EDUCADORA: OLHARES E PRÁTICAS» \\ Pela utopia de Cidades educadoras: POR UM MUNDO ONDE TODOS TENHAM LUGAR
}

\author{
INTRODUCTORY CONSIDERATIONS TO THE MONOGRAPHIC SECTION \\ "The EDUCATING CITY: VIEWS AND PRAXIS"
}

For the utopia of educating cities:

for a world where everyone has a place

\section{Jaqueline Moll \\ Universidade Federal do Rio Grande do Sul, Brasil jaquelinemoll@gmail.com}

RESUMO: O desafio de pensar e construir as cidades como territórios educativos e com novas possibilidades para a convivência humana é o tema deste artigo. Diante de estruturas sociais e económicas violentas e desiguais, este desafio torna-se ainda maior, sobretudo em contextos de países como o Brasil.

Alinhavando matrizes conceituais e experiências vivenciais para a construção do conceito de cidade educadora, parte do entendimento de que, para além de uma proposição metodológica ou uma teoria onírica sobre um modo distinto de organizar as cidades, esta perspetiva constitui uma abordagem política e pedagógica possível para a recomposição dos mosaicos que são as nossas sociedades, na perspetiva de que seja possível convivermos e coabitarmos com as nossas diferenças, produzirmos a nossa vida material e gerarmos dignidade para todos e cada um. Neste sentido propõe tratar-se de um devir permanente, que exige ações intencionais e qualificadas por parte do poder público e da cidadania e que compõe os trânsitos paradigmáticos que estamos a vivenciar como civilização.

Palavras-chave: Cidade Educadora, utopia educativa, convivência humana. 
RESUM: El repte de pensar i construir ciutats com a territoris educatius i amb noves possibilitats de convivència humana és el tema d'aquest article. Davant estructures socials i econòmiques violentes i desiguals, aquest repte esdevé encara més gran, especialment en contextos de països com el Brasil.

Unint les matrius conceptuals $i$ les experiències experiencials per a la construcció del concepte de ciutat educadora, parteix de la comprensió que, més enllà d'una proposta metodològica o una teoria dels somnis sobre una forma diferent d'organitzar les ciutats, aquesta perspectiva constitueix un possible enfocament polític i pedagògic per a la recomposició dels mosaics que són les nostres societats, en la perspectiva de viure i conviure amb les nostres diferències, produir la nostra vida material i generar dignitat per a tots i cadascun. En aquest sentit, proposa ser un esdevenir permanent, que requereix accions intencionals i qualificades per part del poder públic i de la ciutadania i que compon els trànsits paradigmàtics que estem experimentant com a civilització.

Paraules ClaU: ciutat educadora, utopia educativa, convivència humana.

RESUMEN: El desafío de pensar y construir ciudades como territorios educativos y con nuevas posibilidades para la convivencia humana es el tema de este artículo. Frente a las estructuras sociales y económicas violentas y desiguales, este desafío se vuelve aún mayor, especialmente en contextos de países como Brasil.

Uniendo matrices conceptuales y experiencias vivenciales para la construcción del concepto de ciudad educadora, parte de la comprensión de que, más allá de una proposición metodológica o una teoría onírica sobre una forma diferente de organizar las ciudades, esta perspectiva constituye un posible enfoque político y pedagógico para la recomposición de los mosaicos que son nuestras sociedades, en la perspectiva de poder vivir y convivir con nuestras diferencias, producir nuestra vida material y generar dignidad para todos y cada uno. En este sentido, propone ser un devenir permanente, que requiere acciones intencionales y calificadas por parte del poder público y la ciudadanía y que compone los tránsitos paradigmáticos que estamos experimentando como civilización. 
Palabras Clave: Ciudad educadora, utopía educativa, convivencia humana.

ABSTRACT: This article explores the challenge of envisaging and building cities as educational spaces with new possibilities for human coexistence. This challenge is even greater in contexts of violent and unequal social and economic structures, particularly in countries like Brazil.

Combining conceptual nuances and lived experiences to forge the concept of the educating city is grounded on the understanding that, rather than a methodological proposal or an illusory theory of an alternative way of organising cities, this perspective frames a possible political and pedagogical approach to reassemble the mosaics that are our societies, from the vision of living together in harmony with our differences, constructing our material life and enabling dignity for all. This proposal aims to be a constant process of development, which calls for intentional actions approved by public power and society, and that assuages the paradigmatic shifts currently impacting our civilisation.

KeYWORDs: Educating city, educational utopia, human coexistence.

«A educação há de ir aonde vai a vida... há de dar os meios de resolver os problemas que a vida apresentar», José Martí.

$\mathrm{O}^{\mathrm{s}}$ desafio de pensar as cidades como territórios educativos dialoga, de modo visceral, com os desafios do mundo contemporâneo e coloca-se como possibilidade de construir novos horizontes para a convivência humana, num mundo conturbado tanto pela desigualdade económica, geradora de profundos abismos sociais entre ricos e miseráveis, quanto pelos separatismos gerados por preconceitos e ódios antigos e atuais.

Não se trata, portanto, de uma simples proposição metodológica ou de uma teoria onírica sobre um modo distinto de organizar as cidades, mas de uma resposta e de uma abordagem política e pedagógica possível para recompormos e reinventarmos os mosaicos que são as nossas sociedades, na 
perspetiva de que seja possível convivermos e coabitarmos com as nossas diferenças, produzirmos a nossa vida material e gerarmos dignidade para todos e cada um.

Os esforços neste sentido dialogam com um tempo humano e histórico de mudanças profundas que exigem outros patamares de ação pessoal, política e social. Mudanças provocadas pela revolução tecnológica em curso, possibilitadora de uma expansão imensurável da comunicação entre culturas e povos, que certamente contribui para mudanças no campo dos costumes, hábitos e modos de viver a vida.

Apesar dessas mudanças trazerem aspetos positivos, vivemos num mundo afetado pelo retorno de discursos e práticas fascistas, no meio e «a caminho» de confrontos assustadores, que reatualizam e naturalizam a fome, a exploração e a violência simbólica e física, cenas comuns nos campos de concentração nazis, no contexto da segunda guerra mundial.

E estas cenas vão sendo vividas e introjetadas, não a partir de um ato deliberado ou da tomada abrupta do poder, mas como advertiu Eco:

Sería muy cómodo, para nosotros, que alguien se asomara a la escena del mundo y dijera: «iQuiero volver a abrir Auschwitz, quiero que las camisas negras vuelvan a desfilar solemnemente por las plazas italianas!» Por desgracia la vida nos es tan fácil. El ur-fascimo puede volver todavía con las apariencias más inocentes. Nuestro deber es desenmascararlo y apuntar con el índice a cada una de sus formas nuevas, todos los días, en todos rincones del mundo. (2018, p. 60)

Diante deste cenário, pensar a cidade como locus de educação implica um profundo compromisso político para combater as segregações, sejam étnicas, raciais, religiosas, partidárias, ideológicas, de género, de determinadas orientações sexuais ou outras.

Portanto, implica a superação de todas as formas quotidianas de fascismo, abrindo espaços para a construção de modos solidários de existência e para a afirmação das diversidades humanas e do direito de todos e de cada um à dignidade e à beleza.

Neste sentido, a cidade educadora implica uma permanente construção de espaços para que a palavra seja dita e ouvida e de compromissos com a 
qualidade de vida e de desenvolvimento de todos e de cada um, por parte do estado e de suas instituições e também da sociedade através dos seus diferentes atores, agremiações, associações e indivíduos.

Pode-se falar, então, de um devir permanente, que exige ações intencionais e qualificadas por parte do poder público e da cidadania.

Dito de outro modo, trata-se de compreender que a cidade educadora é um permanente vir a ser, que não se conforma a um modo, ato ou método, mas que se faz por ações diferenciadas e conjuntas que materializam a intencionalidade e a compreensão de que educamos e somos educados no conjunto dos fazimentos diários que vivenciamos.

Neste sentido é necessário compreender a ideia de cidade educadora, desde a perspetiva, e como parte, dos processos que compõe os trânsitos paradigmáticos que estamos a vivenciar como civilização.

No mundo ocidental migrámos, paulatinamente, de um modo de vida rural e definido a partir de imperativos religiosos para um modo urbano, influenciado por parâmetros progressivamente pautados pelos avanços da ciência. Agora estamos em pleno processo de migração, e porque não dizer metamorfose, para um modo de estar no mundo que se vai definindo pelos movimentos em curso, entre os quais as revoluções tecnológicas, que incidem sobre o mundo do trabalho, sobre as relações e emoções humanas, sobre a esfera pública e outros setores.

O filósofo brasileiro José Américo Pessanha, num ensaio denominado Imaginação, racionalidade e ética (1993), apresenta o trapézio e o trapezista, como figuras de linguagem para pensar os trânsitos do tempo presente, apontando que estamos a perfazer um movimento de largar um trapézio sem ainda ter agarrado o outro...

Não temos mais os absolutos que tínhamos para nos garantir algum apoio estável, algum ponto fixo na nossa compreensão. Não temos onde engatar o ponto fixo, a rede de proteção o bon dieu do cartesianismo (...) não podemos nos estranhar, ao contrário, nos encontramos num abraço adorável e fraterno que é o ato do conhecimento. (p. 24)

Nesta perspetiva, estamos em movimento e em compasso de espera, mesmo que esta espera seja feita pela própria vida em movimento. Cabe-nos 
realizar profundos processos reflexivos, neste «entre tempos», entre o que foi e o que está para ser.

Nos trilhos abertos por estas reflexões, este texto percorre caminhos e sentidos, desde o ponto de vista das construções pessoais, para a tessitura do conceito e das possibilidades das cidades serem e se fazerem educadoras, mesmo diante de contextos societários repletos de desafios, particularmente no caso brasileiro.

\section{A cidade educadora: a tessitura de um conceito}

[...] a educação é o ponto em que decidimos se amamos o mundo o bastante para assumirmos a responsabilidade por ele e, com tal gesto, salvá-lo da ruína que seria inevitável, não fosse a vinda dos novos e dos jovens. (Hannah Arendt)

O primeiro documento no qual encontrei a ideia de cidade educativa foi, no final dos anos 80, o relatório Aprender a ser organizado pela UNESCO, sob a coordenação de Edgar Faure, formulado desde a perspetiva da educação extraescolar:

Os problemas postos pela instrução e educação de alunos de todas as idades, inclusive os adultos, levam a solicitar múltiplas formas extraescolares de aprendizagem. A educação extraescolar oferece uma ampla gama de possibilidades que devem utilizar-se de maneira produtiva em todos os países. (1972, p. 32)

Até então, tendo terminado a minha formação inicial como professora, nunca tinha pensado na educação para além dos muros escolares. Limitação imposta por uma cultura académica e social restritiva, comum nos países de terceiro mundo, que enquadra e direciona os processos formativos às necessidades e exigências do mundo do trabalho.

Nos demais terrenos da vida, para além da formação profissional, uma certa inconsciência aposta numa «geração espontânea» de saberes, como se os modos e conceitos que transitam na vida social não necessitassem de espaços de construção e reflexão. 
Anos depois, a experiência do Orçamento Participativo vivida no sul do Brasil, na cidade de Porto Alegre, no período de 1989 a 2004, evocava elementos novos para pensar a cidade. Como instrumento de gestão, que permitia e estimulava a participação da população nas decisões acerca das obras e dos investimentos urbanos, acabou por provocar uma importante estratégia pedagógica de leitura diferenciada da cidade pelos seus habitantes. Permitiu e provocou olhares mais sensíveis em relação aos problemas urbanos e as exigências por educação, saúde, habitação, saneamento básico, cultura e desporto.

O orçamento participativo constituiu uma pedagogia própria, configurando elementos vivos de uma cidade que educa e se educa, através de uma metódica intencionalidade do poder público, que por meio de ações e mediações acolhe reivindicações, dialoga com diferentes interesses e enfrenta conflitos vividos no quotidiano da vida urbana.

Esta experiência, infelizmente descontinuada nas administrações que sucederam à Frente Popular que governava Porto Alegre, evocava elementos que insisto em ler no horizonte dos inéditos viáveis, através dos quais Paulo Freire expressa possibilidades de criarmos modos de ser, de viver, de educar que ainda não existem, mas que são gerados nos contextos e conflitos nos quais estamos inseridos.

Na cidade de Barcelona, no período do doutoramento (Moll, 2000), pude vivenciar um pouco da proposição da municipalidade acerca de um projeto educativo de cidade que objetivava articular as áreas de atuação do poder público abrindo, de modo coordenado, os espaços da cidade aos cidadãos em processos permanentes de socialização da informação, inclusão e convite aos espaços públicos.

Pasqual Maragall, prefeito de Barcelona de 1982 a 1997, evocava William Shakespeare (1608), da tragédia Coriolanus para pensar a cidade: $o$ que é a cidade, senão as pessoas, o povo?

A Carta das Cidades Educadoras ou Declaração de Barcelona, escrita em 1990 e depois ratificada e aperfeiçoada na cidade de Bolonha em 1994, firmava a ideia de que a cidade deve desenvolver, para além das suas tradicionais funções económicas, sociais, políticas e de prestação de serviços, uma 
função educadora, no sentido coletivo e permanente da formação, da promoção e do desenvolvimento de todos os seus habitantes, começando pelas crianças e jovens. Textualmente apontava:

A cidade educadora é um sistema complexo em constante evolução e pode exprimir-se de diferentes formas, mas dará sempre prioridade absoluta ao investimento cultural e à formação permanente da sua população. [...] Uma cidade será educadora se oferecer todo o seu potencial de forma generosa, deixando-se envolver por todos os seus habitantes e ensinando-os a envolverem-se nela. (Declaração de Barcelona, 1990)

A partir desta base conceitual e vivencial, passei a pensar a cidade na perspetiva da educação, olhando para o voo no trapézio como parte desta travessia.

Desde a condição de desigualdade que marca a estrutura societária brasileira, a tarefa do poder público na direção da cidade educadora, tem como premissa sine qua o confronto desta estrutura, que se revela em contextos de pobreza e extrema pobreza e em ambientes degradados pela ausência total de planeamento, de sentido de urbanismo e da presença do próprio poder público.

O direito a justos e dignos espaços e tempos de viver, segundo Miguel Arroyo, educador espanhol radicado no Brasil, está estruturalmente vinculado à possibilidade de que os processos educativos aconteçam, sobretudo na perspetiva de uma educação integral.

A ideia política, da qual o conceito de cidade educadora deve estar impregnado (sob pena de converter-se em adereço metodológico) implica processos distributivos que permitam a todos e a cada um, acesso condições materiais básicas para a existência, ou seja, possibilidades de morar, comer, estudar, locomover-se e trabalhar.

Esta mesma ideia política aponta para percursos pedagógicos que intencionalmente devem ser construídos para que a cidade reencontre os seus habitantes e os seus habitantes a reencontrem, para que os invisíveis nas/das periferias ganhem espaço e para que os profundos processos de alienação acerca deste viver juntos/vivendo tão separados, possam ser superados. 
O geógrafo brasileiro Milton Santos contribui para esta compreensão, tanto pela perspetiva da conversão do espaço em território, pelo enraizamento identitário dos sujeitos que vivem nele, quanto pela ideia da cidade policêntrica, conceito revitalizador da clássica relação entre os chamados centros $\mathrm{e}$ as chamadas periferias urbanas.

Se as cidades são as «gentes» que nelas vivem, os espaços públicos ou não, constituídos pela malha sócio-ambiental-cultural constituída pelos museus, cinemas, parques, praças, bibliotecas, câmaras municipais, escolas e outros, precisam ser colocados, de modo intencional, nos itinerários de todos os seus habitantes.

Trata-se, nesta perspetiva de fazer-se cidade educadora, da constituição como escrevi em 2003 - de uma nova esfera pública, que a partir da afirmação e aproximação dos lugares e papéis do Estado e da Sociedade, nas suas mais diversas formas de organização e expressão, trilhe a utopia de um diálogo que inclua todos a cada um:

Integrar-se efetivamente a este movimento implica re-conceitualizar a cidade, entendendo-a no seu emaranhado de ruas, avenidas, praças e prédios, como um território de múltiplas histórias e culturas e por isso, de incontáveis possibilidades educativas. Implica discutir coletivamente quem somos, que necessidades comuns e singulares temos, que presente e que futuro desejamos. Implica assumirmos como diferentes atores sociais do cenário urbano (governos, associações de moradores, movimentos sociais, empresariado, grupos de jovens e de serviços, sindicatos, universidades...) tarefas educativas no sentido de mapear demandas e possibilidades formativas, para oferecer ao conjunto da população inéditos viáveis que permitam fazer da vida algo mais do que ela é.

Esta re-conceitualização pressupõe a compreensão da cidade como uma grande rede ou malha de espaços pedagógicos formais (escolas, universidades, institutos) e informais (teatros, praças, museus, bibliotecas, meios de comunicação, repartições públicas, igrejas, além do trânsito, do ônibus, da rua) que pela intencionalidade das ações desenvolvidas, pode converter a cidade em território educativo, pode fazer da cidade uma pedagogia.

Neste sentido a educação pode ser a chave para a convivência, que pressupõe tanto a compreensão e o respeito as diferenças ideológicas, de raça, de gênero (acrescentaria hoje de orientação sexual), de modo de compreensão da 
vida, quanto o enfrentamento coletivo e concreto dos problemas que nos afligem.

(Moll, 2003)

A atualidade destas reflexões, derivadas da compreensão que vê a educação num horizonte que transcende a escola, como processo permanente, quotidiano, compartilhado e intencional, mostra-se também necessária face às urgências do tempo presente.

David Harvey pensando a cidade, afirma que se a constituímos como a conhecemos, podemos ousar reinventá-la.

As políticas públicas que concretizam o direito de ir e vir, através de processos de mobilidade que permitem deslocamentos intra e inter-bairros, são fundamentais para a concretização deste horizonte formativo, assim como as políticas culturais e as políticas de participação cidadã que permitem dizer a sua palavra, no sentido mesmo de biografar-se, existenciar-se e historicizar-se como escreveu o filósofo brasileiro Ernani Maria Fiori, no prefácio da Pedagogia do Oprimido de Paulo Freire.

A partir deste imbricamento, que nasce das relações entre processos educativos e cidade, desenvolvem-se outros modos de viver e de perceber os tempos e os espaços nos quais a vida acontece no sentido mesmo de garantir o direito de inscrever-se no espaço concreto onde se vive, de narrar-se neste espaço, de narrar este espaço, de construir outros olhares e de sair do lugar da invisibilidade.

Como dimensões deste processo:

- O estado, intencionalmente, pode/deve educar e reeducar-se, inclusive na perspetiva de ações intersetoriais e interdisciplinares que rompem com os lugares temáticos fixos, abrindo possibilidades para ações territoriais que aproximam campos e temas em função das demandas humanas que a escuta sensivel permite apreender.

- A cidade pode reeducar-se, através dos seus coletivos, da comunicação social, das redes sociais virtuais, da ação escolar, dentre outros atores e oferecer-se de modo sistemático e articulado a todos e a cada um, independentemente do lugar de habitação ou condição social dos seus habitantes. 
- A cidade pode ser mapeada nas suas possibilidades educativas e itinerários pedagógicos e estes percursos devem ser oferecidos aos cidadãos.

- As organizações coletivas que animam (animus, do latim alma) a vida nas cidades têm um papel a desempenhar, no sentido da tomada de consciência acerca da responsabilidade de uns em relação aos outros e de todos em relação a todos, na direção de outras ecologias humanas.

- A escola tem um papel específico, nas pontes pedagógicas que pode construir entre os estudantes - de diferentes faixas etárias e o seu território/a sua cidade, pelo seu caráter longitudinal e sistemático na vida dos cidadãos.

- Os sujeitos - cidadãos que vivem a/na cidade podem ser artífices de sua construção como espaço educativo, abrindo-se a processos de desenvolvimento e disposição permanente para aprender e ensinar.

Pensar a cidade, à luz desta compreensão e sob a perspetiva da educação, compõe este esforço e o desafio de incidir sobre as mudanças que estão em curso e nossas próprias possibilidades de reinventar este mundo, nosso modo de viver nele, nossas práticas culturais, políticas e sociais e nossas instituições, como utopias possíveis que nos levam a caminhar. No rumo da reafirmação e do fortalecimento das democracias, o dizer de Galeano: «A utopia está a dez passos, me aproximo dez passos e ela se afasta dez passos mais. Então para que serve a utopia? Para isso mesmo, para nos fazer caminhar.» 


\section{Referências}

Eco, Umberto (2018). Contra el fascismo. Barcelona: Lumen.

Carta das Cidades Educadoras (1990). Carta das Cidades Educadoras, Barcelona: Ajuntamento de Barcelona.

Faure, Edgar (1977). Aprender a ser. 2. a ed. São Paulo: Difusão Editorial do Livro.

Moll, JAQueline (2000). Histórias de Vida, histórias de escola: elementos para uma pedagogia da cidade. Petrópolis: Vozes.

- (2003). Pedagogias nos tempos do orçamento participativo em Porto Alegre: possíveis implicações educativas na ampliação da esfera pública in Verle, João; Brunet, Luciano (orgs). Construindo um novo mundo: Avaliação da experiência do Orçamento Participativo em Porto Alegre - Brasil. Porto Alegre: Guayí. p. 101-125.

Pessanha, José A. (1993). Filosofia e modernidade: racionalidade, imaginação e ética. Cadernos ANPED, Niterói, n. 4, p. 7-36.

Santos, Milton (1996). A urbanização brasileira. 3. a ed. São Paulo: Hucitec. 